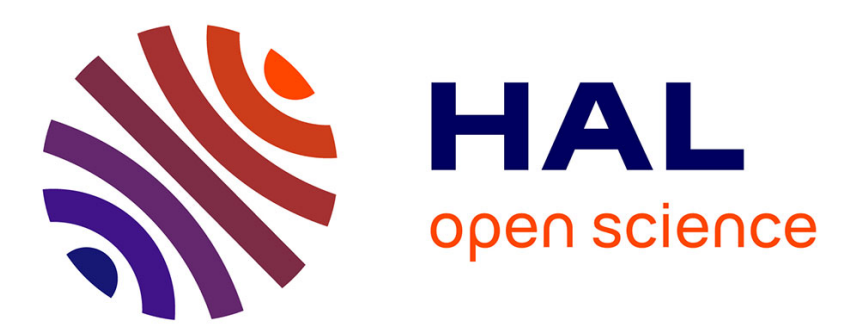

\title{
How to understand better "smart vehicle"? Knowledge Extraction for the Automotive Sector Using Web of Things
}

Mahda Noura, Amélie Gyrard, Benjamin Klotz, Raphaël Troncy, Soumya

Kanti Datta, Martin Gaedke

\section{To cite this version:}

Mahda Noura, Amélie Gyrard, Benjamin Klotz, Raphaël Troncy, Soumya Kanti Datta, et al.. How to understand better "smart vehicle"? Knowledge Extraction for the Automotive Sector Using Web of Things. Semantic IoT: Theory and Applications, pp.303-321, 2021, 10.1007/978-3-030-64619-6_13 . hal-03334677

\section{HAL Id: hal-03334677 \\ https://hal.science/hal-03334677}

Submitted on 4 Sep 2021

HAL is a multi-disciplinary open access archive for the deposit and dissemination of scientific research documents, whether they are published or not. The documents may come from teaching and research institutions in France or abroad, or from public or private research centers.
L'archive ouverte pluridisciplinaire HAL, est destinée au dépôt et à la diffusion de documents scientifiques de niveau recherche, publiés ou non, émanant des établissements d'enseignement et de recherche français ou étrangers, des laboratoires publics ou privés. 


\title{
How to understand better "smart vehicle"? Knowledge Extraction for the Automotive Sector Using Web of Things
}

\author{
Mahda Noura ${ }^{1}$, Amélie Gyrard ${ }^{24}$, Benjamin Klotz ${ }^{3}$, Raphael Troncy ${ }^{3}$, Soumya \\ Kanti Datta ${ }^{3}$, and Martin Gaedke ${ }^{1}$ \\ 1 Technische Universitat Chemnitz, Germany \\ \{mahda.noura, martin.gaedke\}@informatik.tu-chemnitz.de \\ 2 Kno.e.sis, Wright State University, USA, amelie@knoesis.org, \\ 3 EURECOM, Sophia Antipolis, France \\ \{benjamin.klotz, raphael.troncy, soumya-kanti.datta\}@eurecom.fr \\ 4 Trialog, Paris, France
}

\begin{abstract}
How to understand better the knowledge provided by Google results to build future "smart vehicle-centric" applications? What is the knowledge expertise required to build a smart vehicle application (e.g., driver assistance system)?

Automotive companies (e.g., Toyota, BMW, Renault) are employing Internet of Things (IoT) and Semantic Web technologies to model the automotive sector. We aggregate this "common sense knowledge" in an automotive dataset which comprises 42 semantics-based projects between 2005 and 2019. The knowledge is already encoded with knowledge representation languages (e.g., RDF, RDFS, and OWL) and supported by the World Wide Web Consortium (W3C). However, only a subset of those projects share their expertise by publishing their ontologies online. For this reason, at the current time of writing, only 16 ontologies are processable.

Our innovative Knowledge Extraction for the Automotive Sector (KEAS) methodology analyzes what are the most popular terms required to build a smart car, it provides: 1) a set of keyphrase that are synonyms to smart cars to find domain-specific knowledge, 2) synonyms are used to build a corpus of scientific publications to train the k-means machine learning algorithm, 3) a dataset of smart car ontologies that we collected, is analyzed by the k-means algorithm, and 4) the extraction of the most common terms from the ontology dataset for the automotive sector.

Our KEAS findings can be used as a starting point for further domainspecific investigations (e.g., Volvo willing to integrate semantic web) and for future information extraction from structured knowledge.
\end{abstract}

Keywords: Internet of Things (IoT), Knowledge Directory Service, Semantic Ontology Interoperability, Ontology Validation, Reusability, Semantic Web of Things (SWoT), Semantic Web Technologies, Reusable Knowledge. 


\section{Highlights}

- Reusing knowledge already designed for knowledge-based smart car projects.

- Automatic knowledge extraction for the automotive sector based using the $\mathrm{k}$-mean machine learning algorithm.

\section{Introduction}

How to understand better the results provided by Google to build the future "smart vehicle-centric" applications? What is the knowledge expertise required to build a smart vehicle application such as the driver assistance system? According to PC magazin 5 , a smart car is an automobile with advanced electronics. Microprocessors have been used in car engines since the late 1960s and have steadily increased in usage throughout the engine and drivetrain to improve stability, braking and general comfort. According to Gartner's 2018 prediction ${ }^{6}$ "IoT platforms","Autonomous Driving Level 4", and "Knowledge Graphs" are the next challenges for the coming 5-10 years or even beyond.

Automotive companies (e.g., Toyota ${ }^{7}$ [1, BMW [2] [3] 4] [5, Renault [6]) are already employing Internet of Things (IoT) and Semantic Web technologies. BMW Autonomous Driving in the Internet of Cars Summer Schoo 8 demonstrates interest in IoT technologies and even Semantic Web technologies [3. BMW is designing the Vehicle Signal and Attribute (VSSO) ontology ${ }^{9}$ [2] and the Vehicle Driving Context (VDC) ontology ${ }^{10}$ auto.schema.org ${ }^{11}$ defines 4 types, 20 properties and 3 enumeration values (in December 2018) which clearly shows that the knowledge could be extended. Volvo is investigating the integration of semantic web technologies (RDF, Linked Data, ontologies) for automomous car: 12 .

Acquiring knowledge about automotive (e.g., technological survey, reading scientific publications and staying updating with the latest progresses) is a timeconsuming approach. The survey about transportation ontologies [7], published in 2018, can be easily enriched with numerous ontologies that we collected within the LOV4IoT ontology catalog for IoT and transport ${ }^{13}$ that we designed. The survey 7] compares 11 ontologies according to 7 criteria: 1) Precision (relationship diversity, axiom complexity), 2) Evaluation, 3) Knowledge management services, 4) Generality, 5) Granularity, 6) Competence, and 7) Span.

We designed the "semantic-based IoT smart vehicle" LOV4IoT dataset thats collects common sense knowledge for the automative sector. We classified 42

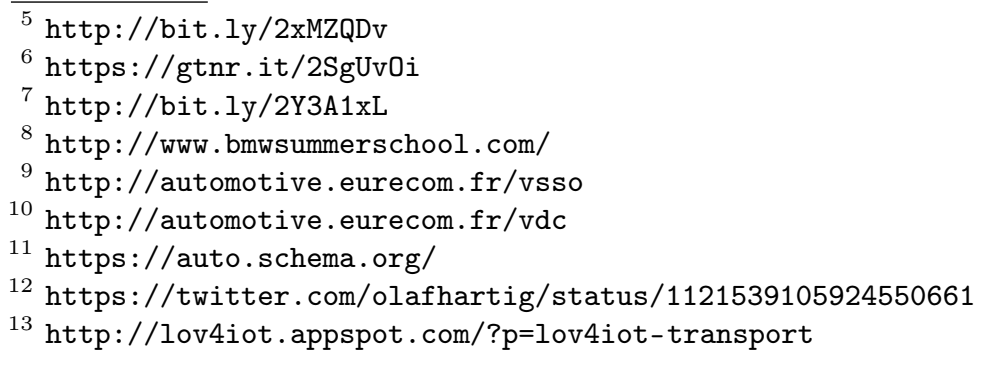


projects between 2005 and 2019 since they claim that the knowledge is already encoded with knowledge representation languages (e.g., RDF, RDFS, and OWL) and supported by the World Wide Web Consortium (W3C). However, only a subset of those projects share their expertise by publishing their ontologies online. For this reason, at the current time or writing, our dataset comprises only 16 processable ontologies.

Motivation are as follows:

- M1: Why cannot we find the entire PhD thesis, entitled "Using Ontologies and Intelligent Systems for Traffic Accident Assistance in Vehicular Environments" 8] published in 2014 relevant for smart car on the first page of Google results? It is provided on the third page on Google ${ }^{14}$ whereas years of research and expertise are explained in the thesis.

- M2: How to find more knowledge than Google for a specific domain (e.g, smart vehicle)?

- M3: Why does the Google Knowledge Graph cannot provide results to handle the synonyms used for the automotive domain (e.g., smart car, smart vehicle, smart mobility)?

Research questions are as follows:

- RQ1: How to automatically analyze structured knowledge (e.g., ontologies) from existing projects? We found that numerous projects designed ontologies that are also explained within scientific publications can be analyzed.

- RQ2: What are the most used entities (e.g, concepts, instances) within those ontologies? Statistical methods can help to achieve this task.

Contributions are as follows: Our innovative Knowledge Extraction for the Automotive Sector (KEAS) methodology understands the "common sense knowledge" required to build smart vehicle applications which provides:

1. C1: A set of keyphrase synonyms for the smart vehicle domain to find domain-specific knowledge in past or current projects that published their results within scientific publications,

2. C2: Synonyms are used to build a corpus of scientific publications to train the k-means machine learning algorithm,

3. C3: A dataset of smart car ontologies is built and analyzed by the k-means algorithm to cluster knowledge, and,

4. C4: The extraction of the most common knowledge for the automotive sector. We refined a previous methodology [9] that we applied to the smart vehicle domain in this book chapter.

Structure of the Paper: Section 3 introduces the related work. Section 4 explains our Knowledge Extraction for the Automotive Sector (KEAS) methodology to find the relevant knowledge already implemented within ontologies. Section 5 evaluates our proposed approach. Section 6 concludes the paper and provides future work.

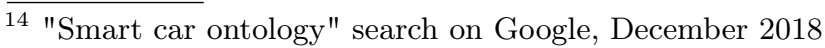




\section{Background and Related Work}

Toyota Motor Europe (TME) ${ }^{15}$ uses auto.schema.org in their web site to describe cars to sell. For instance, 7000 URLs including the type "Car" from the TME web site have been encoded and indexed by Google.

auto.schema.org ${ }^{16}$ defines 4 types (BusOrCoach, CarUsageType, Motorcycle, MotorizedBicycle), 20 properties (accelerationTime, acrissCode, bodyType, emissionsCO2, engineDisplacement, enginePower, engineType, fuelCapacity, meetsEmissionStandard, modelDate, payload, roofLoad, seatingCapacity, speed, tongueWeight, torque, trailerWeight, vehicleSpecialUsage, weightTotal, wheelbase) and 3 enumeration values (DrivingSchoolVehicleUsage, RentalVehicleUsage, TaxiVehicleUsage) (in December 2018). It clearly shows the the knowledge could be extended.

OpenSensingCity ${ }^{17}$ references 12 ontology URLs relevant to mobility: Transport, travel domain, transportation networks, transport disruption, soft mobility, PASSIM, location concept for travel support system, route, ASK-IT, road, transit.

SAREF4AUTO is being specified and supported by the ETSI standard; the ontology code and specification cannot be found yet, only those slides can be investigated [10] at the time of this writing.

Conclusion: Ontology-based projects are introduced in Table 1 when ontologies are publicly available, that we analyze thanks to the KEAS methodology in Section 4.2. Other projects related to the topic that cannot be used since ontologies are not shared (as depicted in Table 2). Although scientific publications were really interesting, those ontologies have been discarded since we cannot find their ontology online (see Table 2 ).

\section{Knowledge Extraction for the Automotive Sector (KEAS) Methodology}

The long-term vision of the Knowledge Extraction from IoT-related ontologies project is depicted in Figure 1. In this paper, we are focused on the Ontology code extraction algorithm and the Ontology Dataset components applied to the smart vehicle domain.

\subsection{Survey methodology to collect ontologies for smart vehicles}

Scientific Publication Corpus and Ontology Dataset. We collected a total of 42 projects from 2005 to 2018 more or less related to smart vehicles. However, the aggregation of knowledge has been done since several years. The methodology

15 http://bit.1y/2Y3A1xL

16 https://auto.schema.org/

17 http://ci.emse.fr/opensensingcity/ns/result/domain/transportation/ 


\begin{tabular}{|c|c|c|c|c|}
\hline Authors & Year & Expertise & $\mathrm{OA}$ & Reasoning \\
\hline Klotz et al. 2] [4] & 2018 & BMW: Vehicle Signal and Attribute & $\checkmark$ & $\checkmark$ OWL restriction \\
\hline OpenSensingCity & 2018 & $\begin{array}{l}\text { Parking Scenario } \\
\text { Bike Scenario }\end{array}$ & $\checkmark$ & $\begin{array}{l}x \\
x \\
\end{array}$ \\
\hline CityPulse [11] 12] & 2016 & Traffic Analysis Scenario & $\checkmark$ & - \\
\hline $\begin{array}{l}\text { Gyrard et al. }[3] \\
\text { BMW Summer School }\end{array}$ & 2014 & Transport Ontology & $\checkmark$ & $\checkmark$ Jena rules \\
\hline Morignot et al. [13] & 2013 & Autonomous Vehicle Assistance & $\checkmark$ & $\checkmark$ foggy $->$ mode manual \\
\hline $\begin{array}{l}\text { Zhao et al. [14] } \\
\text { [15] [16] [17] [1] }\end{array}$ & $2017-2014$ & Toyota: Safe Autonomous Driving & $\checkmark$ & $\checkmark \mathrm{SWRL}$ \\
\hline Lecue et al. [18 & 2014 & STAR-CITY: Transport Ontology & $\checkmark \checkmark$ & - \\
\hline $\begin{array}{l}\text { Ruta et al. [19] } \\
\text { [20] 21] }\end{array}$ & 2017 & $\begin{array}{l}\text { iDriveSafe Ontology } \\
\text { Mafalda projet ( } 3 \text { ontologies })\end{array}$ & $\checkmark$ & $\checkmark$ OWL restrictions \\
\hline Maarala [22] & 2017 & Traffic Ontology & $\checkmark$ & $\checkmark 16$ rules, OWL restrictions \\
\hline Bermejo et al. 23] & 2013 & Road Traffic Management Ontology & $\checkmark$ & $\begin{array}{l}\checkmark 77 \text { rules/actions } \\
\text { (SWRL DLSafe rule in the ontology) }\end{array}$ \\
\hline Dardailler et al. & 2012 & W3C Road Accident Ontology & $\checkmark$ & $x$ \\
\hline Corsar et al. 24 & 2015 & Transport Disruption Ontology & $\checkmark$ & $\checkmark$ OWL restriction \\
\hline Codescu et al. 25] & 2011 & Open Street Map and Route Planning & $\checkmark$ & $x$ \\
\hline $\begin{array}{l}\text { Grausberg, } \\
\text { Fuchs et al. 26] 27 }\end{array}$ & 2008 & Driver Assistance System Ontology & $\checkmark$ & $\begin{array}{l}\checkmark \text { OWL restriction } \\
\text { (rule speed max min) }\end{array}$ \\
\hline Hepp et al. & - & W3C Vehicle Sales Ontology & $\checkmark$ & XNo owl:Restriction \\
\hline
\end{tabular}

Table 1. Ontology-based IoT automotive projects used in the dataset that we analyzed.

Legend: Ontology Availability (OA)

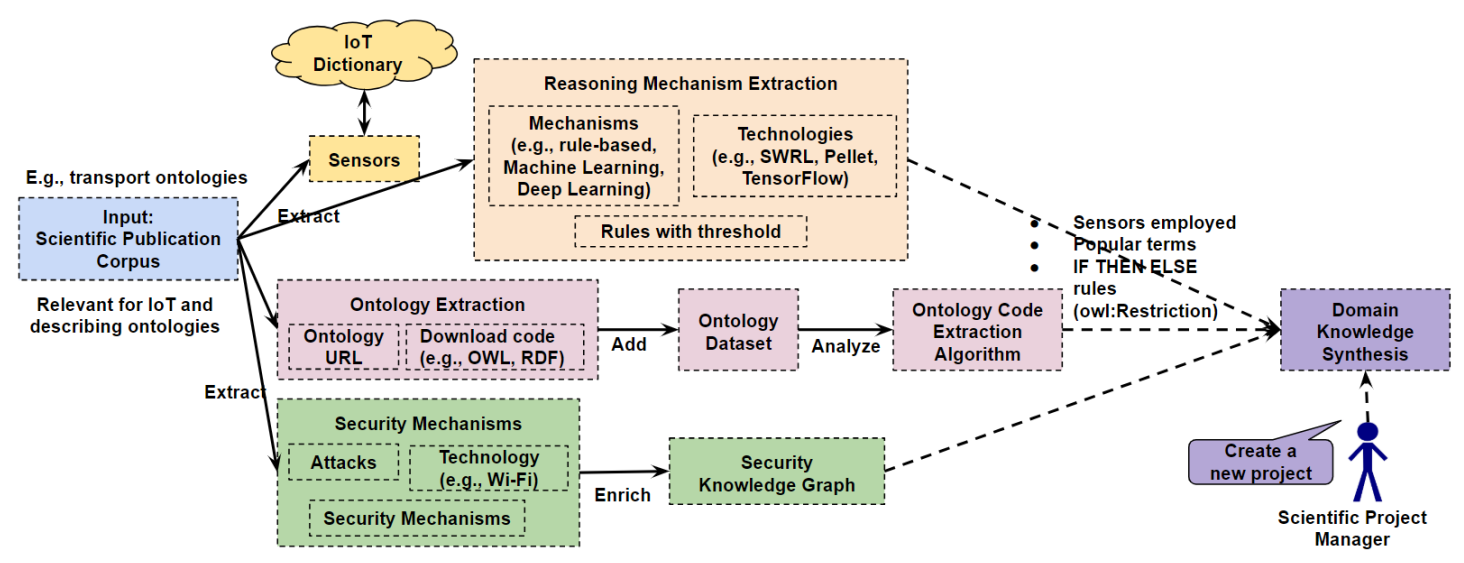

Fig. 1. Knowledge extraction from scientific publications and ontologies (Long-term vision) 


\begin{tabular}{|c|c|c|c|c|}
\hline Authors & Year & Expertise & $\mathrm{OA}$ & Reasoning \\
\hline Wetterwald et al. [10] & 2019 & SAREF4AUTO & $x$ & $x$ \\
\hline Katsumi et al. [7] & 2018 & Survey - 11 ontology referenced & $x$ & $x$ \\
\hline Fernandez et al. 28 & 2016 & Automatic traffic lights settings & $x$ & $x$ \\
\hline Armand et al. [6] & 2014 & Renault: Driving Assitance & $x$ & $\checkmark 14$ SWRL rules \\
\hline Villalba et al. & 2014 & VEACON: Vehicular Accident & $x$ & - \\
\hline 8] 29] 30 & & CAOVA: Car Accident for VANETs & $x$ & - \\
\hline Stocker et al. [31 32 & 2014 & Road vehicle classification & $x$ & $\checkmark$ Rule-based inference (vehicle type) \\
\hline Ebers et al. [33] & 2013 & VANETs ontology & $x$ & $x$ \\
\hline $\begin{array}{l}\text { Mnasser, De Oliveria, } \\
\text { Houda, Zidi et al. } \\
{[34] \text { [35] 36] 37] }}\end{array}$ & 2013 & Transportation ontology & $x$ & $\checkmark$ Jess engine for SWRL rules \\
\hline Li et al. 38 & 2012 & Car ontology (in chinese) & $x$ & $x$ \\
\hline Calavia et al. [39] & 2012 & Traffic ontology & $x$ & $\checkmark$ Semantic reasoning, SWRL rules \\
\hline Madkour et al. [40] & 2011 & Ontology of transportation networks & $x$ & $x$ \\
\hline Hamilton et al. [41] & 2013 & Ontology of transportation networks & $x$ & $\checkmark$ Pellet, SWRL, Jess \\
\hline Feld, Muller et al. [42 & 2011 & Automative, distance between cars & $x$ & $x$ \\
\hline Wang et al. [43] & 2011 & Traffic accident ontology & $x$ & $x$ \\
\hline Hulsen et al. 44 & 2011 & Ontology for Driver Assistance & $x$ & $\checkmark$ RacerPro \\
\hline Berdier et al. [45] & 2011 & Ontology for Urban mobility & $x$ & $x$ \\
\hline Kannan et al. 46] & 2010 & $\begin{array}{l}\text { Intelligent driver } \\
\text { assistance system for vehicle }\end{array}$ & $x$ & $\checkmark$ Pellet reasoner (consistency) \\
\hline Baumgartner et al. [4] & 2010 & Ontology for Situation Awareness & $x$ & $\checkmark 10$ rules \\
\hline Liu et al. [48] & 2010 & Road surveillance system & $x$ & $\checkmark$ SWRL rules (inform, alert) \\
\hline Niaraki et al. [49] & 2009 & personalized route planning & $x$ & $x$ \\
\hline Yue et al. [50] & 2009 & Traffic accident & $x$ & $x$ \\
\hline Zhai et al. [51] & 2009 & Traffic information & $x$ & $\checkmark($ dryness, dampness $)$ \\
\hline Sun et al. 52] & 2009 & Smart car & $x$ & $x$ \\
\hline Belhadef et al. 53 & 2009 & Urban geographical information system & $x$ & $x$ \\
\hline Regele et al. [54] & 2008 & $\begin{array}{l}\text { Autonomous Driving System: } \\
\text { trajectory planning, traffic coordination }\end{array}$ & $x$ & $x$ \\
\hline Mair, Eigner et al. [55] & 2008 & $\begin{array}{l}\text { Collision avoidance in VANETs } \\
\text { Ontology (in German) }\end{array}$ & $x$ & $x$ \\
\hline Cheng et al. [56] & 2008 & Transportation & $x$ & $\begin{array}{l}\checkmark \text { Ontology-based reasoning (Racer) } \\
\text { rule-based reasoning } \\
(\text { Jess, LISP, SWRLJessTab) }\end{array}$ \\
\hline Hu et al. 57 & 2007 & oil & $x$ & $x$ \\
\hline Lorenz et al. [58 & 2005 & Ontology of transportation networks & $x$ & $x$ \\
\hline
\end{tabular}

Table 2. Other Ontology-based IoT automotive projects that cannot be employed since ontologies are not available (even upon request). Legend: Ontology Availability $(\mathrm{OA})$ 
has been search on Google and Google Scholar a set of specific keywords, as an example those keyphrases: 1) start with ontology-based, 2) finished with ontology, or 3) start with semantic-based. Keyphrases are as follows:

- Automotive, Automated vehicle, Autonomous vehicle, Car, Cars, Vehicle, Vehicles, Smart car.

- Transportation, Transportation networks, Transport, Public transportation.

- Road Traffic Management, Roads, Road system, Traffic Jam Avoidance.

- Personalized Route Planning, Route Planning.

- Car Driving Assistance, Driver Assistance Systems, Advanced Driver Assistance, Intelligent Driver Assistance System.

- Vehicular Ad Hoc Networks (VANETs), Wireless Vehicular Networks (VANETs), Vehicle-to-Vehicle (V2V), Vehicle-to-Vehicle Networks, Vehicular Networks.

- Road Accident, Vehicular Accident, Traffic Accidents, Road Safety, Car Accident Prevention, Accident Rescue Mission.

- Intersection Assistance.

- Vehicle Context-aware Services.

- Pedestrian Detection.

- Car Pooling Recommendation System.

For the set of scientific publications, we focused on the following criteria:

- Are ontology URLs available within the scientific article? Frequently, URLs are missing. Authors have been contacted to retrieve ontology code and we enriched the dataset when receiving positive answers. 1 summarizes the 16 ontologies that share their ontologies online, which is the smart vehicle ontology dataset later analyzed. Other ontology-based projects are referenced in Table 2, unfortunately, the ontologies cannot be processed yet since they are not accessible.

- Are sensors mentioned within the paper?

- Are there reasoning mechanisms and already defined rules to interpret data generated by the smart vehicle applications?

- Is the reference section provide more resources to investigate? We enrich our scientific publication dataset accordingly (e.g., LOV4IoT-transport knowledge repository).

The main difference between our survey and the existing ones, is that our survey is the result of a continuous enrichment of the LOV4IoT ontology catalog since 2012 and we provide tools to support the reuse of the survey outcome (e.g., dump of ontology code). Meanwhile, we are aware of Systematic Literature Review (SLR) guidelines such as [59, 600, 61.

\subsection{Building the corpus of knowledge for the transportation domain}

To train the dataset, we need to build a corpora of knowledge for the transportation domain. word2vec helps in transforming texts from either scientific publications or ontologies into vectors that can be processable by machine learning algorithms. word2vec performs the training of the term embeddings and the process of building a word2vec model for all identified unique words. The 
word2vec algorithm is based on neural networks and builds a vocabulary from a pre-training text model and attaches the vector representations to each word. Around 20 of the terms were not part of the pre-trained model thus we removed those terms from the list of words. The output of this step is the word embedding vector space representation. The genism python library is used to implement word2vec.

Transport Ontology Dataset: We have collected 16 ontologies that can be downloaded and analyzed (as depicted in Table 11): 2 ontologies are excluded since they were in Chinese or German. We released the list of ontology URLs within an online tabl ${ }^{18}$. For the convenience of the developers, we created a tutorial web page (http://lov4iot.appspot.com/?p=queryTransportOntologiesWS) to either use the web service or easily download the dump of the ontology code that we collected.

For instance, the developer can query the web service http://lov4iot. appspot.com/perfectoOnto/getOntoDomain/?domain=Transportation which returns the list of the projects relevant for the smart car domain that we collected within the LOV4IoT ontology catalog for transport19 it includes: the name of the project and the ontology, the ontology URL, and additional information such as the scientific publication describing the ontology (see Figure 2). The web service is more up-to-date with latest ontologies collected, compared to the dump file. However, when the projects are not maintained anymore, the URLs can become dead links, which is the reason we store the ontology code within dump files.

\section{Evaluation}

Planned Evaluation: To identify the most popular concepts from smart car ontologies, the proposed KEAS methodology is evaluated in an empirical study which includes an analysis that gives a complete overview of the performance of the descriptiveness of the most popular concepts (in the same way it has been done in our Knowledge Extraction for the Web of Things (KE4WoT) work 62]). The objective of this experiment is to identify if the keywords provided by KE4WoT can sufficiently describe existing ontologies.

Ontology Selection: 16 smart car ontologies are collected from LOV4IoT for evaluation purposes (Table 1). The most important ontologies in each domain have been selected according to the following criteria:

- Citations of the scientific publications describing the ontology (e.g., the SSN ontology v1 63] has more than 1000 citations): higher is the number, better the ontology might be. However, this criteria cannot be applied to recent publications.

18 shorturl.at/jEIQ7

19 http://lov4iot.appspot.com/?p=lov4iot-transport 


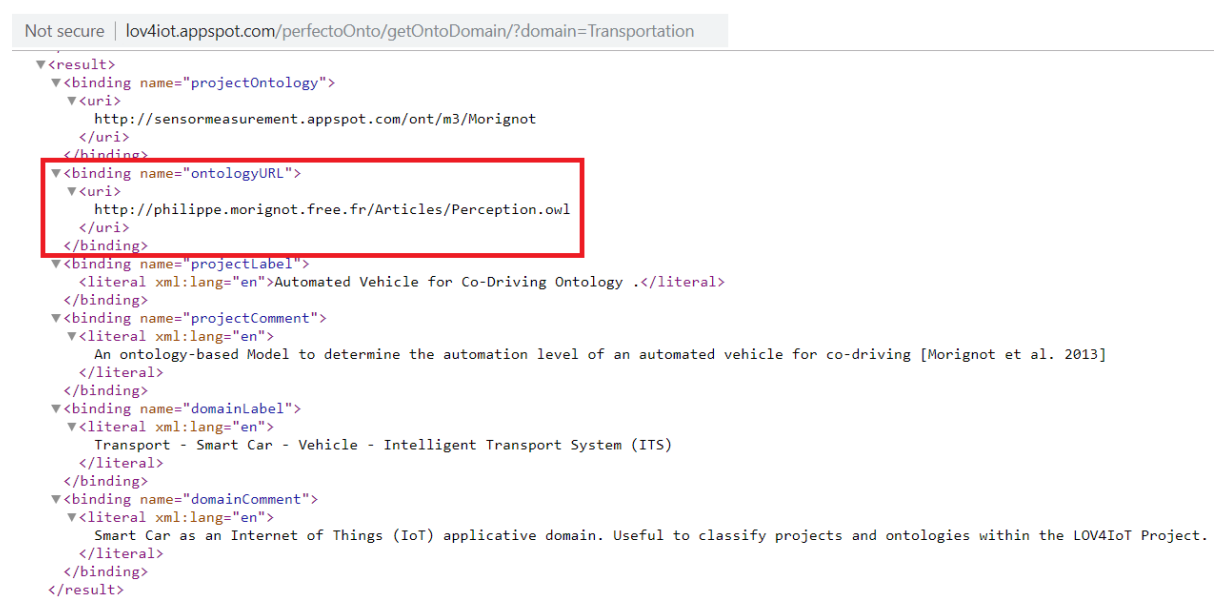

Fig. 2. Web service example to automatically retrieve ontology-based projects for the smart car domain: ontology URLs and scientic publications

- Journal impact factor and conference ranking: higher the ranking is, better would be the ontologies. Within the references section, the ranking is added for publications cited and classified within Table 1 and Table 2

- Recent publications increase the chance to have the authors maintaining the ontology and integrating previous ontologies.

- Ontologies disseminated in standardizations (e.g., W3C Web of Things ontology ${ }^{20}$, W3C SSN/SOSA ontology [64], ETSI M2M SAREF ontology [65]) can be considered as more reliable.

- Industrial partners involved, the project is considered more impactful, and the implementation is more reliable.

- Domain experts involved (not computer scientists) since they share their human expertise.

- Ontology code that can be downloaded, because, in science, the experiments should be replicable, following the FAIR (Findability, Accessibility, Interoperability, and Reuse) principles.

Ground Truth Dataset Design: Domain experts can participate in the questionnaire to design the ground truth (a similar questionnaire for smart cities, weather, and smart home is available onlin $\oint^{21}$ see [62]) for detailed information). Experts were either involved in developing smart car ontologies or are an open audience having the domain expertise to describe each ontology using three keywords. The participants' level of expertise in the automotive domain and knowledge engineering, is asked in a Likert scale of five levels, from 'totally

20 https://www.w3.org/TR/wot-thing-description/

21 https://bildungsportal.sachsen.de/survey/limesurvey/index.php/716626/

lang-en 
disagree' to 'totally agree'. The experts are given the list of ontologies (through a series of figures from the ontology classes in Protege) in different domains to select the top three keywords that best describes that ontology in relation to the keywords that were obtained from the main concepts in the generated clusters. Domain experts chose keywords among a total number of keywords in our evaluation form.

\section{Conclusion and Future Work}

The Systematic Literature Survey (SLS) in any research topics is a time-consuming approach. Finding knowledge returned by Google results still require a huge work on learning, classification and summarizing. To ease this time-consuming task, we built a "common sense knowledge" dataset for the automotive sector comprising 42 projects between 2005 and 2019. However, only 16 ontologies are processable and published online with knowledge representation standards. Our innovative Knowledge Extraction for the Automotive Sector (KEAS) methodology aims to analyze the most popular knowledge required to build smart vehicle applications by applying the k-means machine learning algorithm to a dataset of 16 ontologies that we collected.

This work highly encourages researchers to share their reproduceable experiments by publishing online their smart vehicle ontologies. As a future work, we would like to re-generate an ontology to aggregate and unify the knowledge from existing ontologies. Furthermore, we would like to automatically recognize the sensors mentioned within ontologies and scientific publications to maintain our IoT dictionnary, and reasoning mechanisms used to detect abnormal sensor data and execute actions.

\section{Acknowledgment}

This work has partially received funding from the European Union's Horizon 2020 research and innovation programme under grant agreement No 857237 (Interconnect). The opinions expressed are those of the authors and do not reflect those of the sponsors.

\section{References}

1. L. Zhao, R. Ichise, S. Mita, and Y. Sasaki, "An Ontology-Based Intelligent Speed Adaptation System for Autonomous Cars," in Joint International Semantic Technology Conference (Conference rank not found). Springer, 2014.

2. B. Klotz, R. Troncy, D. Wilms, and C. Bonnet, "VSSo - A Vehicle Signal and Attribute Ontology (Short Paper)," in SSN Workshop at ISWC. CEUR Workshop Proceedings, 2018.

3. A. Gyrard, C. Bonnet, and K. Boudaoud, "Ontology-based Intelligent Transportation Systems," in BMW Summer School 2014, Autonomous Driving in the Internet of Cars, 2014. [Online]. Available: http://sensormeasurement. appspot.com/publication/PosterBMW.pdf 
4. B. Klotz, R. Troncy, D. Wilms, and C. Bonnet, "Generating Semantic Trajectories Using a Car Signal Ontology," in The Web conference (WWW, A-rank conference), 2018.

5. B. Klotz, S. K. Datta, D. Wilms, R. Troncy, and C. Bonnet, "A car as a semantic web thing: Motivation and demonstration," in Global IoT Summit GIoTS, colocated with the IoT Week, 2018.

6. A. Armand, D. Filliat, and J. Ibañez-Guzman, "Ontology-Based Context Awareness for Driving Assistance Systems," in Intelligent Vehicles Symposium (IEEE IV, B-rank conference). IEEE, 2014.

7. M. Katsumi and M. Fox, "Ontologies for Transportation Research: A Survey," Elsevier Transportation Research Part C: Emerging Technologies Journal (IF: 5.775 in 2018), 2018.

8. J. B. Villalba, "Using Ontologies and Intelligent Systems for Traffic Accident Assistance in Vehicular Environments," Ph.D. dissertation, 2014.

9. M. Noura, A. Gyrard, S. Heil, and M. Gaedke, "Concept Extraction from the Web of Things Knowledge Bases," in International Conference WWW/Internet 2018. Elsevier, 2018, Outstanding Paper Award.

10. M. Wetterwald, "Slides: Towards a SAREF extension for Automotive. W3C Workshop on Data Models for Transportation."

11. D. Puiu, P. Barnaghi, R. Toenjes, D. Kümper, M. I. Ali, A. Mileo, J. X. Parreira, M. Fischer, S. Kolozali, N. Farajidavar et al., "Citypulse: Large scale data analytics framework for smart cities," IEEE Access, 2016.

12. S. Kolozali, M. Bermudez-Edo, D. Puschmann, F. Ganz, and P. Barnaghi, "A knowledge-based approach for real-time iot data stream annotation and processing," in IEEE iThings conference, 2014.

13. E. Pollard, P. Morignot, and F. Nashashibi, "An Ontology-based Model to Determine the Automation Level of an Automated Vehicle for Co-Driving," in International Conference on Information Fusion, 2013.

14. L. Zhao, R. Ichise, Z. Liu, S. Mita, and Y. Sasaki, "Ontology-Based Driving Decision Making: A Feasibility Study at Uncontrolled Intersections," IEICE TRANSACTIONS on Information and Systems, 2017.

15. L. Zhao, R. Ichise, T. Yoshikawa, T. Naito, T. Kakinami, and Y. Sasaki, "OntologyBased Decision Making on Uncontrolled Intersections and Narrow Roads," in IEEE intelligent vehicles symposium (IV). IEEE, 2015.

16. L. Zhao, R. Ichise, S. Mita, and Y. Sasaki, "Core Ontologies for Safe Autonomous Driving," in International Semantic Web Conference (Posters \&5 Demos) (ISWC, A-rank conference), 2015.

17. —_ "Ontologies for Advanced Driver Assistance Systems," in The 35th Semantic Web \& Ontology Workshop (SWO), 2015.

18. F. Lécué, S. Tallevi-Diotallevi, J. Hayes, R. Tucker, V. Bicer, M. L. Sbodio, and P. Tommasi, "Star-city: semantic traffic analytics and reasoning for city," in Proceedings of the 19th international conference on Intelligent User Interfaces. ACM, 2014.

19. M. Ruta, F. Scioscia, F. Gramegna, and E. Di Sciascio, "A Mobile KnowledgeBased System for On-Board Diagnostics and Car Driving Assistance," in International Conference on Mobile Ubiquitous Computing, Systems, Services and Technologies (UBICOMM, B-rank conference). Citeseer, 2010.

20. M. Ruta, F. Scioscia, F. Gramegna, G. Loseto, and E. Di Sciascio, "Knowledgebased Real-Time Car Monitoring and Driving Assistance," in SEBD. Citeseer, 2012 . 
21. M. Ruta, F. Scioscia, G. Loseto, A. Pinto, and E. Di Sciascio, "Machine Learning in the Internet of Things: a Semantic-enhanced Approach," Semantic Web Journal, 2017.

22. A. I. Maarala, X. Su, and J. Riekki, "Semantic reasoning for context-aware internet of things applications," IEEE Internet of Things Journal, 2017.

23. A. Bermejo, J. Villadangos, J. Astrain, and A. Cordoba, "Ontology Based Road Traffic Management," in Intelligent Distributed Computing VI. Springer, 2013.

24. D. Corsar, M. Markovic, P. Edwards, and J. D. Nelson, "The Transport Disruption Ontology," in International Semantic Web Conference (ISWC, A-rank conference). Springer, 2015.

25. M. Codescu, G. Horsinka, O. Kutz, T. Mossakowski, and R. Rau, "Osmonto - an Ontology of OpenStreetMap Tags," State of the map Europe (SOTM-EU), 2011.

26. S. Fuchs, S. Rass, B. Lamprecht, and K. Kyamakya, "A Model for Ontology-Based Scene Description for Context-Aware Driver Assistance Systems," in Proceedings of the 1st international conference on Ambient media and systems, 2008.

27. S. Fuchs, S. Rass, and K. Kyamakya, "Integration of ontological scene representation and logic-based reasoning for context-aware driver assistance systems," Electronic Communications of the EASST, 2008.

28. S. Fernandez and T. Ito, "Using SSN Ontology for Automatic Traffic Light Settings on Intelligent Transportation Systems," in IEEE International Conference on Agents (ICA). IEEE, 2016.

29. J. Barrachina, P. Garrido, M. Fogue, F. J. Martinez, J.-C. Cano, C. T. Calafate, and P. Manzoni, "CAOVA: A Car Accident Ontology for VANETs," in IEEE Wireless Communications and Networking Conference (WCNC, A-rank conference). IEEE, 2012.

30. J. Barrachina, P. Garrido, M. Fogue, F. J. Martinez, and et al., "VEACON: A Vehicular Accident Ontology Designed to Improve Safety on the Roads," Elsevier Journal of Network and Computer Applications (IF: 5.273 in 2018), 2012.

31. M. Stocker, M. Rönkkö, and M. Kolehmainen, "Making Sense of Sensor Data Using Ontology: A Discussion for Road Vehicle Classification," 2012.

32. M. Stocker, M. Rönkkö, and et al., "Situational Knowledge Representation for Traffic Observed by a Pavement Vibration Sensor Network," Transactions on Intelligent Transportation Systems, 2014.

33. S. Ebers, H. Hellbuck, D. Pfisterer, and S. Fischer, "Short paper: Collaboration Between VANET Applications Based on Open Standards," in Vehicular Networking Conference (VNC, B-rank conference). IEEE, 2013.

34. K. M. De Oliveira, F. Bacha, H. Mnasser, and M. Abed, "Transportation Ontology Definition and Application for the Content Personalization of User Interfaces," Elsevier Expert Systems with Applications Journal (IF: 4.292 in 2018), 2013.

35. A. Zidi and M. Abed, "A Generalized Framework for Ontology-Based Information Retrieval: Application to a Public-Transportation System," in International Conference on Advanced Logistics and Transport (ICALT, B-Rank Conference). IEEE, 2013.

36. H. Mnasser, F. Gargouri, and M. Abed, "Towards an Intelligent Information System of Public Transportation," in International Conference on Advanced Logistics and Transport (ICALT, B-Rank Conference). IEEE, 2013.

37. M. Houda, M. Khemaja, K. Oliveira, and M. Abed, "A public Transportation Ontology to Support User Travel Planning," in International Conference on Research Challenges in Information Science (RCIS, B-rank conference). IEEE, 2010. 
38. G. Li, D. Ma, and V. Loua, "Fuzzy Ontology Based Knowledge Reasoning Framework Design," in International Conference on Software Engineering and Service Science (ICSESS, ranking not found). IEEE, 2012.

39. L. Calavia, C. Baladrón, J. M. Aguiar, B. Carro, and A. Sánchez-Esguevillas, "A Semantic Autonomous Video Surveillance System for Dense Camera Networks in Smart Cities," Sensors, 2012.

40. M. Madkour and A. Maach, "Ontology-Based Context Modeling for Vehicle Context-Aware Services," Journal of Theoretical and Applied Information Technology, 2011.

41. A. Hamilton, E. J. González, L. Acosta, R. Arnay, and J. Espelosín, "SemanticBased Approach for Route Determination and Ontology Updating," Engineering Applications of Artificial Intelligence, 2013.

42. M. Feld and C. Müller, "The Automotive Ontology: Managing Knowledge Inside the Vehicle and Sharing it Between Cars," in International Conference on Automotive User Interfaces and Interactive Vehicular Applications (Conference rank not found). ACM, 2011.

43. J. Wang and X. Wang, "An Ontology-Based Traffic Accident Risk Mapping Framework," in International Symposium on Spatial and Temporal Databases. Springer, 2011.

44. M. Hülsen, J. M. Zöllner, and C. Weiss, "Traffic Intersection Situation Description Ontology for Advanced Driver Assistance," in Intelligent Vehicles Symposium (IV). IEEE, 2011.

45. C. Berdier, "Road System Ontology: Organisation and Feedback," in Ontologies in Urban Development Projects. Springer, 2011.

46. S. Kannan, A. Thangavelu, and R. Kalivaradhan, "An Intelligent Driver Assistance System (I-DAS) for Vehicle Safety Modelling Using Ontology Approach," International Journal of UbiComp (UbiComp, A-rank conference), 2010.

47. N. Baumgartner, W. Gottesheim, S. Mitsch, W. Retschitzegger, and W. Schwinger, "BeAware!- Situation Awareness, the Ontology-Driven Way," Elsevier Data \& Knowledge Engineering Journal (IF: 1.583 in 2018), 2010.

48. C.-H. Liu, K.-L. Chang, J. J.-Y. Chen, and S.-C. Hung, "Ontology-Based Context Representation and Reasoning Using OWL and SWRL," in Conference on Communication Networks and Services Research (CNSR, B-rank conference). IEEE, 2010 .

49. A. S. Niaraki and K. Kim, "Ontology Based Personalized Route Planning System Using a Multi-Criteria Decision Making Approach," Elsevier Expert Systems with Applications Journal (IF: 4.292 in 2018), 2009.

50. D. Yue, S. Wang, and A. Zhao, "Traffic Accidents Knowledge Management Based on Ontology," in International Conference on Fuzzy Systems and Knowledge Discovery (FSKD, B-rank conference). IEEE, 2009.

51. J. Zhai, Y. Chen, Y. Yu, Y. Liang, and J. Jiang, "Fuzzy Semantic Retrieval for Traffic Information Based on Fuzzy Ontology and RDF on the Semantic Web," JSW, 2009.

52. J. Sun, Z.-h. Wu, and G. Pan, "Context-Aware Smart Car: From Model to Prototype," Springer Journal of Zhejiang University-Science A, 2009.

53. H. Belhadef and M. Kholladi, "Urban Ontology-Based Geographical Information System," Journal of Theoretical and Applied Information Technology, 2009.

54. R. Regele, "Using Ontology-Based Traffic Models for More Efficient Decision Making of Autonomous Vehicles," in International Conference on Autonomic and Autonomous Systems (ICAS, B-rank conference). IEEE, 2008. 
55. R. Eigner and G. Lutz, "Collision Avoidance in VANETs - An Application for Ontological Context Models," in International Conference on Pervasive Computing and Communications (PerCom, A-Rank Conference). IEEE, 2008.

56. G. Cheng, Q. Du, and H. Ma, "The Design and Implementation of Ontology and Rules Based Knowledge Base for Transportation," in International Conference on Computer Science and Software Engineering (CASCON, B-rank conference). IEEE, 2008.

57. Y. Hu, Z. Wu, and M. Guo, "Ontology Driven Adaptive Data Processing in Wireless Sensor Networks," in international conference on Scalable Information Systems. ICST (Institute for Computer Sciences, Social-Informatics), 2007.

58. B. Lorenz, H. J. Ohlbach, and L. Yang, "Ontology of Transportation Networks," 2005.

59. D. Budgen and P. Brereton, "Performing Systematic Literature Reviews in Software Engineering," in International conference on Software engineering. ACM, 2006.

60. B. Kitchenham, R. Pretorius, D. Budgen, O. P. Brereton, M. Turner, M. Niazi, and S. Linkman, "Systematic Literature Reviews in Software Engineering- A Tertiary Study," Information and software technology, 2010.

61. G. Rizzo, F. Tomassetti, A. Vetro, L. Ardito, M. Torchiano, M. Morisio, and R. Troncy, "Semantic Enrichment for Recommendation of Primary Studies in a Systematic Literature Review," Digital Scholarship in the Humanities, 2017.

62. M. Noura, A. Gyrard, S. Heil, and M. Gaedke, "Automatic Knowledge Extraction to Build Semantic Web of Things Applications," 2019.

63. M. Compton, P. Barnaghi, L. Bermudez, R. Garcia-Castro, O. Corcho, S. Cox, J. Graybeal, M. Hauswirth, C. Henson, A. Herzog et al., "The ssn ontology of the w3c semantic sensor network incubator group," Web Semantics: Science, Services and Agents on the World Wide Web, 2012.

64. A. Haller, K. Janowicz, S. Cox, D. Le Phuoc, K. Taylor, and M. Lefrançois, "Semantic Sensor Network Ontology," W3C Recommendation, 2017. [Online]. Available: https://www.w3.org/TR/2017/CR-vocab-ssn-20170711/

65. L. Daniele, M. Solanki, F. den Hartog, and J. Roes, "Interoperability for smart appliances in the iot world," in International Semantic Web Conference. Springer, 2016.

\section{Appendix}

\subsection{Clustering Results}


[assessment, viewpoint, analysis, classification, investigation, survey]

[course, begins, advance, back, go, last, step, put, forward, ahead, end, initial, first, start, meeting, date, point]

[new, several, multiple, relevant, previous, following, involved, additional, interest, number]

[making, made, make, driven, maker, trees]

[manually, add, rule, search, update, meta, validity, observable, valid, static,

match, set, inference, predefined]

[asset, recovery, upgrading, installation, improvement, reconstruction, evacuation,

progress, preventative, cleaning, cycle, preparation, plan, repair, maintenance,

planning, inspection, construction, operation]

[held, manager, play, played, reports, participant, board, report]

[articulated, autonomous, automation, robot, navigation, adas, assistance, platooning,

automated, driving, cruise, cooperative]

[blizzard, ssn, record, sampling, reading, observation, description, measurement, weather]

[aid, main, dedicated, common, includes, created, inter, based, shared, communications, built, general, technical, communication, sharing, works, connected, establishment, open, extension, involving, working, address, work, related, active]

[declares, org, info, title, uri, doi]

[publisher, guest, pub, ski, books, cert, email, comments, photo, fi, signed, creator]

- [access, using, usage, offer, store, delivers, availability, storage, collection,

delivered, users, avail, used, use, available, consumption]

[checks, sender, message, check, massage]

[build, economy, urban, buildings, spaces, community, security, mobility, environment, city, environmental, network, smart, transport, transportation, management, public, building, infrastructure]

[history, attraction, adult, birth, young, currency, age]

[layout, riot, parameters, execute, steps, hardware, details, software, module,

model, execution, run, mode, configuration, version, setup, running]

[order, dealing, involves, problem, human, language, also, tools, parts, since,

part, possibility, kind]
[rescue, customs, prohibited, bank, reserve, administrative, airport, court, insurer,

[rescue, customs, prohibited, bank, reserve, administrative, airport, court, insur
company, owned, authority, agency, organization, rights, insurance, post, engaged, police, site, facility]

Fig. 3. Cluster Results Part I

[decision, stand, turn, u, action, right, left, drive, v]

[done, specified, meets, fitness, standard, defined, selected, zone, modified]

[note, minor, attributed, remaining, major, recognized, indirect, associated, subject,

primary, secondary, cause, contributor]

[registration, manual, fee, household]

[school, office, informal, town, college, bureau, arts, chair, arena, turkish, department,

theme, unive

[relationship, belongs, vocabulary, element, named, property, document, attribute,

relation, entity, item, restriction, operator, feature, object, category, class,

event, name, agent, type]

[strings, obj, slots, atomic, sequence, datatype, columns, rows, row, equivalence,

matrix, timestamp, tree, block]

[willingness, owners, owner, owns, man, people, child, person, contact, place, thing,

body]

[hard, carrying, restrict, protected, regular, covered, maintain, closure, allowed,

'yes', non, pre, internal, temporary, local, free, direct, short, long]

[library, identification, barcode, label, rfid, image, code, qr, bar, card, tagging,

id]

[reliability, performance, accuracy, uptime, precision, quality, visibility, success]

[black, white, color, box, style]

[attack, leak, anti, detection, fault]

[march, demonstration, campaign, regional, spur, national, program, catalyst]

[impossible, unknown, deviated, weigh, witness, disruptive, wrong, even, bad, behind,

abnormal]

[experience, behavior, situation, nature, dynamic, ability, self, phenomenon, pattern,

characteristics, changing, behaviour, game, activity, conditions, context, term,

perception, condition]

[convenience, walking, outdoor, infotainment, occupant, occupants, motorized, pedestrian,

disabled, health, living, care, pedestrians, safety, emergency]

[spacial, descent, variant, fourier, sax, symbolic, wavelet, cosine, piecewise,

hybrid, derivation, blinding, gauss, lm, var, approximation, linear, discrete, dimensionless]

[crowd, music, mobile, video, remote, obd, media, multimedia, cctv, biometric, smartphone,

touch, nfc, phone, computer, tv, electronic, machine, text, telephone, voice]

Fig. 4. Cluster Results Part II 


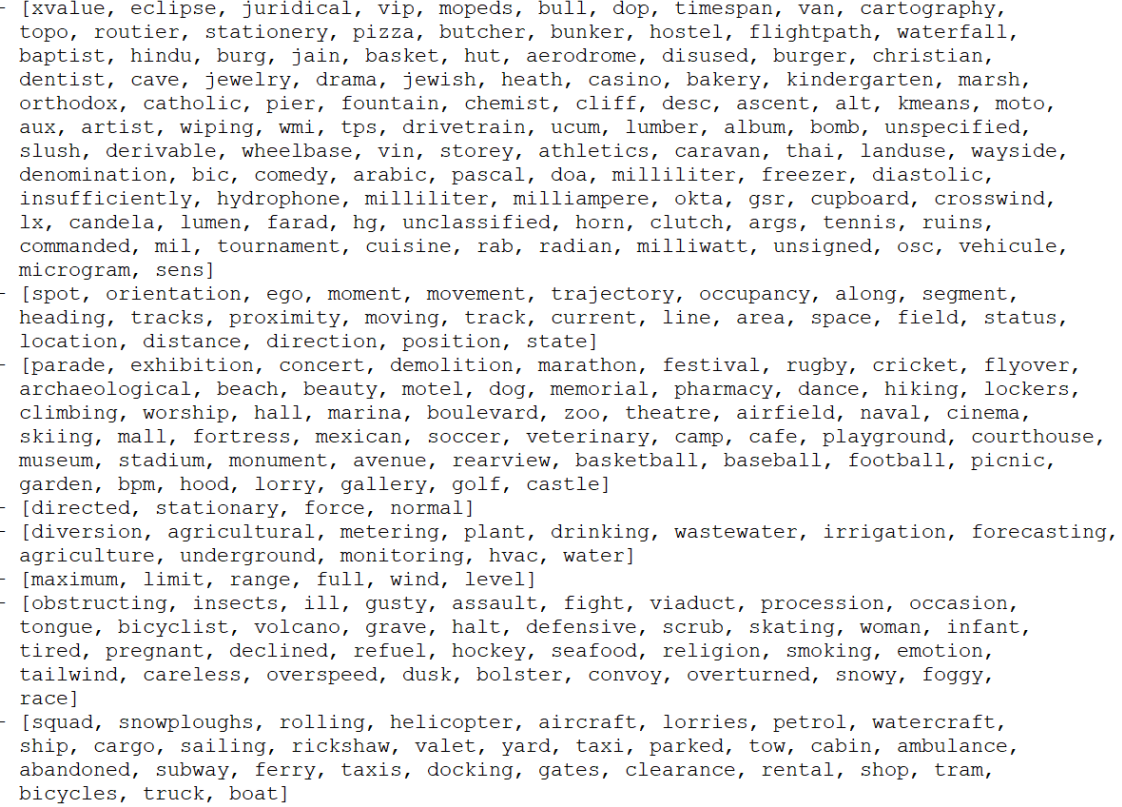

Fig. 5. Cluster Results Part III

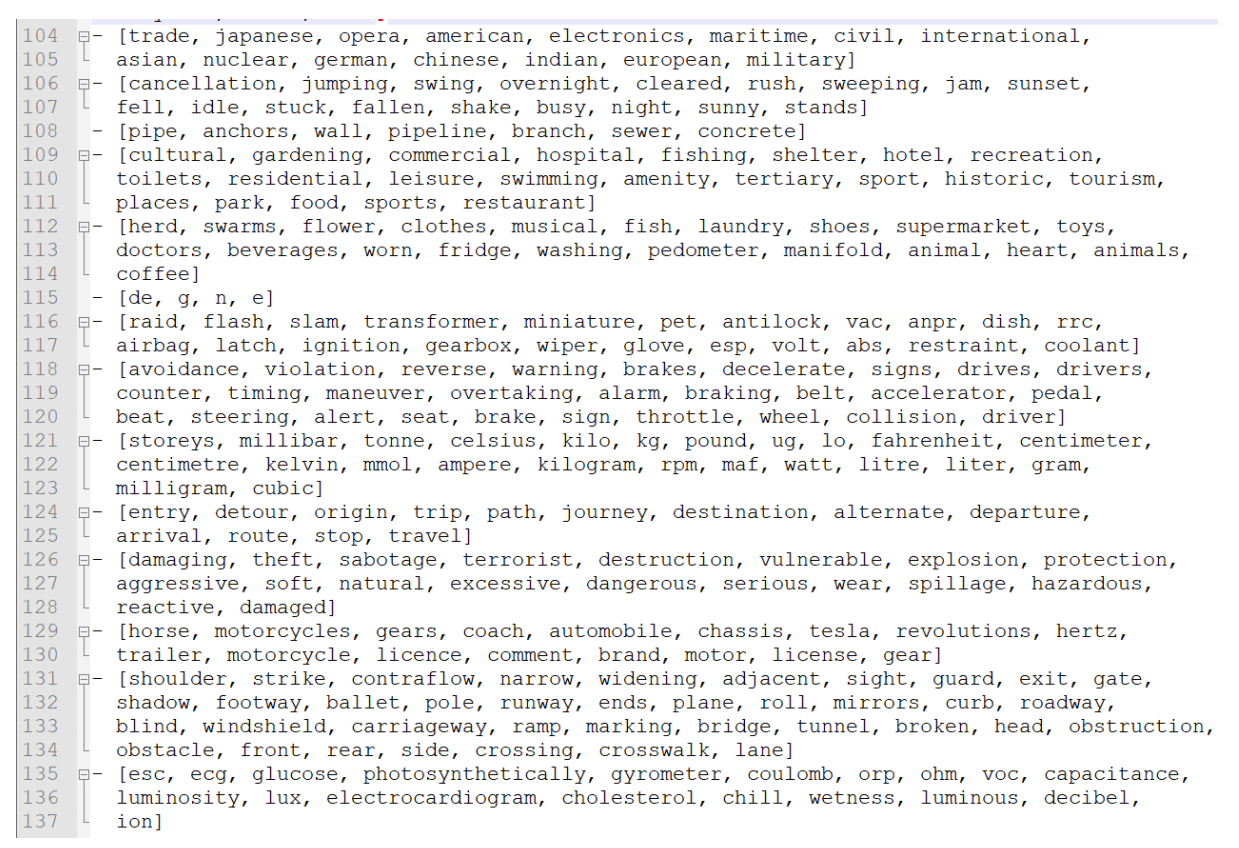

Fig. 6. Cluster Results Part IV 
[patches, pavements, spray, chippings, gritting, carriageways, gantry, cables, film, laying, resurfacing, litter, blasting, spun, packed, ball, seating, navigable, curbs, rails, rocks, bowls, wash, ditch, wood, apron, drain, stone, cable, bench, hydrant, furniture, cycleway, old, pad, pavement, grass, cutting, rock, beds, leafs, sloped, drained, gravel, dome,

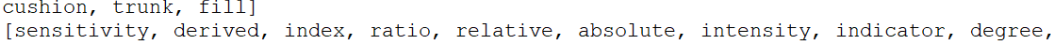
weight

[axles, foot, axle, mm, miles, inch, kilometers, kilometres, diameter, travelled, odometer, millimeter, millimetre, kilometre, kilometer, square, metre

[delivery, offering, business, platform, marketplace, services, connection, cloud, service]

[deceleration, speeds, drag, stress, traction, bending, burst, displacement, friction, pitch, angular, vertical, torque, tension, rotational, velocity, instantaneous, motion, longitudinal, lateral, sound, angle, acceleration, speed]

[fully, single, sub, scale, multi, tire, preferred, micro, second]

[min, dtc, evap, ref, ra, dist, temp, max, avg, dew]

[market, difficulty, barrier, political, obstacles, potential, barriers, gap]

$[\mathrm{c}, \mathrm{b}, \mathrm{w}, \mathrm{k}]$

[permanently, slide, roof, doors, outside, entrance, chamber, house, kiosk, closed, opening, rooms, room, refrigerator, empty, curtain, locked, container, lock, door] [cross, stability, boundary]

[sleet, flooding, tornadoes, storms, slippery, intermittent, floods, avalanches, showers, overflow, weighing, thunderstorms, hurricane, smog, gusts, blowing, disturbance, salting, frost, hail, shower, icy, storm, rainy, smoke, fire, heavy, dust, rain] [earthquake, impacts, events, crash, landslips, damages, insured, severity, severe, roadworks, extreme, risk, injury, closures, incident, damage, hazard, failure, accident, danger]

[odometry, localization, compass, barometer, gyro, positioning, speedometer, yaw,

laser, microwave, seismometer, radar, optical, magnetometer, ultrasonic, gyroscope,

accelerometer, magnetic, clock, tilt, camera, gps, mirror, beam, detector, thermometer]

[diesel, production, fossil, recycling, renewable, goods, ethanol, gross, billion, million, chains, oil, waste, fuel]

[undefined, leaves, sink, flux, leaf, stream, fog, source]

Fig. 7. Cluster Results Part V

[glare, taxiway, shed, photovoltaic, illuminance, dimming, lighting, solar, window,

lamp, shade, sun, lights, light]

[pylon, sensors,

device, sensor]

[controlled, loops, carries, actuated, diagnostic, signals, terminal, appliance,

controller, command, actuator, engine, control, switch, system, meter]

[mountain, alpine, bay, glacier, rink, grassland, geological, valley, coastline,

river, canal, reef, dam, wetland, forest, waterway, pan, delta]

[duration, peak, hours, millisecond, instant, interval, year, times, day, volume,

mileage, minute, hour, unit, time, per]

[generator, generated, input, variable, interface]

[dense, moderate, large, localized, isolated, clear, near, around, fair, poorly, medium, weak, strong, poor, presence, high, low]

[deep, pool]

[buses, transit, intersections, bikes, bike, vehicles, motorway, signalling, lanes, street, toll, highway, roadside, train, rail, passenger, railway, congestion, bicycle, car, bus, station, parking, traffic, road, vehicle]

[noise, pollutant, co, emission, pollution, carbon, gas, energy]

[difference, mean, equivalent, inflation, altitude, median, percent, elevation, density, variation, slope, height, error, width, length, values, average, value, rate, count]

[oxide, monoxide, dioxide]

[cold, avalanche, drifts, vegetation, patchy, subsidence, spring, uneven, freeze, warmer, snowfall, dry, rainfall, land, falling, melting, fall, cloudy, winds, cloudiness, cover, winter, wet, ground, ice, freezing, soil, precipitation, snow, surface]

[heat, molsture, salinity, resistance, conductance, skin, ph, conductivity, ambient, blood, humidity, pressure, temperature]

[toxic, fumes, fresh, coal, hydro, radioactive, methane, mg, oxidation, calcium, nitrate, ppm, gaseous, ammonium, salt, sodium, potassium, ammonia, combustion, ozone, oxygen, sulphur, alcohol, volatile, organic, nitrogen, concentration]

[big, fast, pace, accelerate, smooth, transform, backward, slow]

[artwork, points, coordinates, map, spatial, latitude, longitude, reference]

[tidal, barometric, global, atm, radiation, atmospheric]

Fig. 8. Cluster Results Part VI 


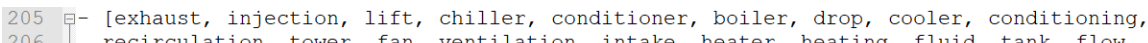
206 recirculation, tower, fan, ventilation, intake, heater, heating, fluid, tank, flow, 208 - [overhead, queuing, latency, cons, delay, throughput, handover]

209 E- [filter, materials, particle, aggregate, particles, compound, material, mass, chemical,

210 quantity]

211 E- [charging, cell, backup, charge, electrical, capacity, battery, voltage, load, electric, 212 power]

213 E- [payload, cc, timer, pulse, wi, par, pc, packet, transmission, uplink, frequency

214 downlink, signal, link, mhz]

215 E-[impact, reduced, influence, depends, result, increase, decrease, ect, distribution, 216 negative, reduction, loss, change, total, show]

Fig. 9. Cluster Results Part VII 